\title{
Marsupialization and sclerotherapy with povidone iodine and ethanol of a branchial remnant cyst in an Arabian filly
}

\author{
Riccardo RINNOVATI ${ }^{1}$, Barbara BIANGHIN BUTINA ${ }^{1}$, Jessica BIANGHI ${ }^{2}$, \\ Armando FOGLIA ${ }^{1}$, Carlotta LAMBERTINI $^{1}$ and Sara DEL MAGNO ${ }^{1}$ \\ ${ }^{1}$ Department of Veterinary Medical Sciences, University of Bologna, 40064, Ozzano dell'Emilia, BO, Italy \\ ${ }^{2}$ Private practitioner, Pesaro-Urbino, 61121, Italy
}

\begin{abstract}
Branchial remnant cysts are an uncommon cause of masses of the throatlatch area in horses. Two methods of treatment have been proposed in literature, both with complications. This manuscript proposes a method (marsupialization and sclerotherapy) for the treatment of a cyst in a 1.5-year-old Arabian filly. Diagnosis was made by ultrasonographic, radiographic and endoscopic examinations, revealing an anechoic fluid-filled structure and a welldefined capsule not in communication with other structures. After emptying the cyst, the skin was sutured circumferentially to the cyst wall; it was then flushed first with a solution of ethanol and povidone-iodine, then with sterile saline. Eight months after surgery, the filly had no recurrence of the cyst and the stoma was healed.
\end{abstract}

Key words: Arabian horse, branchial remnant cyst, marsupialization, sclerotherapy

\author{
J. Equine Sci. \\ Vol. 29, No. 2 \\ pp. $43-46,2018$
}

In horses, the branchial apparatus develops between 4 and 6 weeks of gestation. It consists of 4 well-defined and 2 rudimentary pairs of branchial arches that form the head and neck region of the embryo $[14,20]$.

The arches are covered externally by ectoderm and internally by endoderm; the mesoderm, which lies between them, contains a dominant artery and nerve as well as a cartilage rod and muscle. Branchial arches are separated by five clefts on the external ectodermal side of the embryo and five pouches on the internal endodermal side of the embryo [11]. In fish, these structures form gills, but in mammals, the clefts and pouches are gradually obliterated by invasion of the surrounding mesenchyme, and the branchial apparatus develops into the mature structures of the head and the neck [20].

Branchial anomalies result from incomplete obliteration of these clefts and pouches $[1,20]$ or their failure to regress and may occur as cysts, sinus tracts, or fistulae [16]. Several branchial apparatus anomalies have been reported in humans $[2,16]$. Branchial cysts are uncommon embryonic

Received: November 17, 2017

Accepted: April 25, 2018

*Corresponding author. e-mail: riccardo.rinnovati2@unibo.it (C2018 Japanese Society of Equine Science

This is an open-access article distributed under the terms of the Creative Commons Attribution Non-Commercial No Derivatives (by-nc-nd) License. (CC-BY-NC-ND 4.0: https://creativecommons.org/licenses/ by-nc-nd/4.0/) anomalies in horses, mice, cats, dogs and cattle [8-10, 19]. In horses, the problem has been described in a several cases: in 6 foals with branchial cysts of probable second and third arch origin [5, 7, 10, 17, 18] and in 5 mature horses [17].

Two procedure options for treating branchial remnant cysts are described in the literature: surgical removal and marsupialization with iodine sclerotherapy [5-7, 10, 17, 18]. Surgical resection of branchial cysts led to excellent outcome in 4 cases $[5,7,13]$; however, most adult horses treated via surgical excision developed right laryngeal hemiplegia postoperatively [17]. In a single case report, marsupialization and iodine sclerotherapy were used as a viable alternative to surgical excision; however, in the abovementioned case, the entire cyst lining was removed following the sclerotherapy [18]. The following case report describes an alternative method for sclerotherapy to treat branchial remnant cysts.

Case history: A 1.5-year-old Arabian filly was admitted for a prominence in the cranial portion of the neck. The owners confirmed that the foal had a normal appearance at birth. Eleven months later, the owners noticed a small enlargement in the right side of the throat area, which in the subsequent 6 months further increased in size. On admission, physical examination revealed a large smooth bulging mass measuring $20 \mathrm{~cm}$ long and $15 \mathrm{~cm}$ wide in the right larynx region (Fig. 1). The filly did not present respiratory distress or abnormal respiratory noises. On palpation, the mass was warm and moveable under the skin, and it did not 


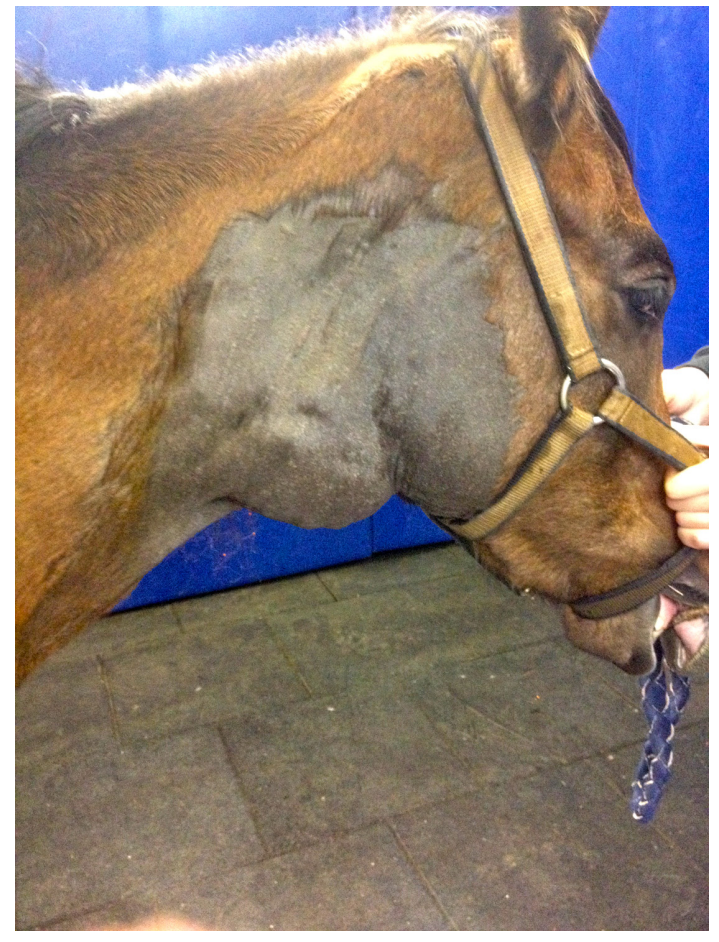

Fig. 1. The foal with the mass in the throatlatch area.

elicit any signs of pain. The bulging structure was situated 5 $\mathrm{cm}$ caudal to the right emi-mandible. The trachea and larynx were displaced to the left by the mass. The filly's respiratory rate was 20 breaths $/ \mathrm{min}$, heart rate was 60 beats $/ \mathrm{min}$, and rectal temperature was $38.0^{\circ} \mathrm{C}$. Results of thoracic and tracheal auscultation were normal; no wheezes, crackles, or other abnormal sounds were heard. Hematologic and serum biochemical variables were within normal limits.

Diagnosis: Ultrasonographic examination of the mass revealed an anechoic fluid-filled structure with small hyperechoic fluctuant particles and a well-defined hyperechoic capsule not in communication with other structures and distant from the thyroid gland.

Endoscopy of the guttural pouches revealed no abnormalities, and laryngeal function was normal. Radiographs revealed a large well-defined space-occupying structure with homogeneous content, ventral to the first and second cervical vertebra. The mass was causing displacement of the proximal portion of the trachea.

Hair over the mass was clipped, and the skin was prepared in an aseptic manner. A small area of skin on the ventrolateral aspect of the mass was infiltrated with $1.5 \mathrm{ml}$ of $2 \%$ lidocaine hydrochloride, and an 18-gauge needle was used to obtain an aspirate. Aspiration yielded $20 \mathrm{ml}$ of a yellow viscous fluid. A sample was submitted for cytologic evaluation and aerobic and anaerobic bacterial culture. The

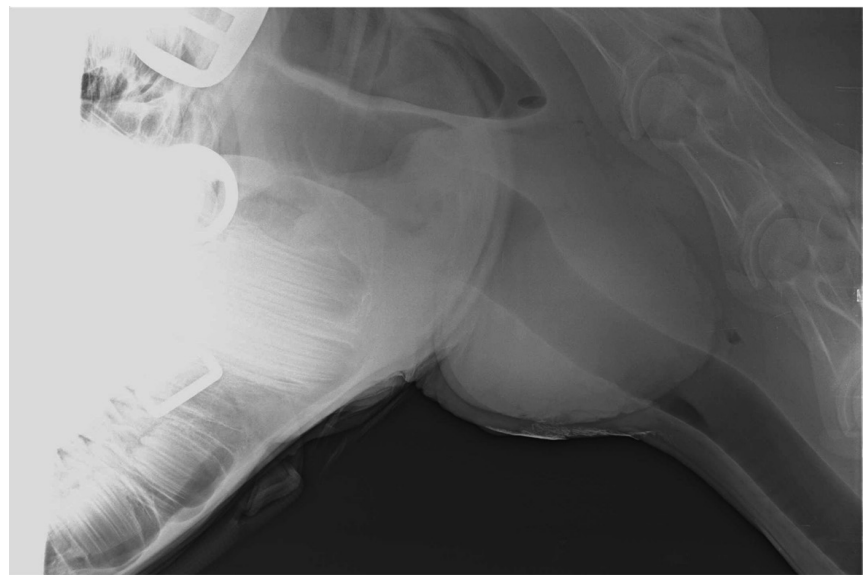

Fig. 2. Radiograph showing the cyst with contrast medium.

fluid revealed the presence of squamous epithelium, and it was classified as an exudate with low cellularity; cells consisted predominantly of macrophages phagocytosing cell debris and neutrophils, while rare lymphocytes and eosinophils were present; no cholesterol crystals were found in the cyst fluid. Aerobic and anaerobic bacterial culture did not yield any growth.

Contrast radiographs were taken with the foal standing to rule out the possibility of any sinus tract in the surrounding soft tissue. Twenty millilitres of ioversol 64\% were injected into the cyst, and radiographs of the cervical region were taken. The contrast medium remained within the cyst, indicating that the cyst did not communicate with other structures (Fig. 2).

A diagnosis of branchial remnant cyst was made, and it was decided to proceed with marsupialization of the cyst and alcohol-iodine sclerotherapy.

Surgical technique: The right jugular vein was catheterized, and the filly was sedated with detomidine hydrochloride $(0.02 \mathrm{mg} / \mathrm{kg})$. The entire ventral part of the cyst was infiltrated with $2 \%$ lidocaine hydrochloride and aseptically prepared for surgery. A $5 \mathrm{~cm}$ incision was made, and the cyst emptied of the fluid, with $190 \mathrm{ml}$ of fluid flowing out. The cyst wall was sutured circumferentially to the skin with a simple interrupted pattern using 2-0 monofilament nylon sutures.

An 18 French Foley catheter was inserted into the cyst, the balloon was inflated with $5 \mathrm{ml}$ of air, and the catheter was fixed to the skin margin using a 0 monofilament nylon suture. The cavity was flushed with $20 \mathrm{~m} l$ of ethanol and $180 \mathrm{ml}$ of povidone-iodine $10 \%$ (Betadine ${ }^{\circledR}$ ) solution. This solution was left to act in situ for $15 \mathrm{~min}$. After that, the cyst was flushed repeatedly with $200 \mathrm{~m} l$ of sterile saline $(0.9 \%$ $\mathrm{NaCl}$ ) three times. This procedure was repeated once a day 
for the further 5 days.

After that, the Foley catheter was removed and replaced with a Penrose drainage. After 4 days, the drain was removed. Sutures were removed after 14 days. The marsupialization site was allowed to heal by second intention, and 30 days after surgery, the stoma was closed.

The filly was treated with trimethoprim-sulfamethoxazole ( $30 \mathrm{mg} / \mathrm{kg}$ orally once daily) for 20 days.

Before discharge, guttural pouch endoscopy was repeated in order to check for any possible secondary iatrogenic damage in the surrounding structures, but no abnormalities were observed.

Outcome: Eight months after surgery, the filly was examined again. She maintained a normal appetite and attitude. No recurrence of the fluid-filled cyst was observed. There was no evidence of discharge, and the stoma was closed and healed with a good cosmetic appearance.

Branchial remnant cysts are an uncommon cause of masses of the throatlatch area in both juvenile and adult horses. There are at least four theories about their origins, but it is generally accepted that these defects are derived from remnants of the fetal branchial cleft, arch, or pharyngeal pouch or from a combination of these embryonic tissues [14].

In horses, two methods of treatment have been proposed for this condition: surgical removal or marsupialization and sclerotherapy with iodine solution $[5,7,10,17,18]$.

The definitive treatment for branchial apparatus anomalies in humans is complete surgical excision, as these lesions will not resolve spontaneously. If not resected, there is a high incidence of infection, and if incompletely resected, there is a high incidence of recurrence [20].

In the horse, complete surgical excision of branchial cysts can be difficult because of the proximity of vital structures such as the recurrent laryngeal nerve, vagosympathethic trunk, jugular vein and carotid arteries [18].

The idea to attempt to sclerotize the epithelial lining with iodine avoids the risks of surgical excision. On the other hand, it can lead to a relapse, and at the end of the therapy, it could be necessary to remove surgically the cyst lining. Failure to remove the entire cyst lining can lead to abscess formation [18]. The sclerotic agent used in horses for treatment of branchial remnant cysts is $1 \%$ povidoneiodine solution.

In human medicine, the choice of sclerotic agent is dictated by the surgeon's preference, with a tendency not to use alcohol in lymphoceles that abut vital structures such as vessels and nerves. The use of multiple concurrent sclerotic agents has been reported in humans [4, 12, 15], and various agents have been investigated, including marine mussel proteins [3].

In our case report, we selected to use both ethanol and iodine, as they have a high sclerosing capacity. Given the proximity of nervous and vascular structures, we consider that pure ethanol could be dangerous. For this reason, we supplement ethanol with iodine as a diluent.

Using an operating protocol with this mixture of povidone-iodine and ethanol and with the application of a passive drain at the end of the five days of sclerotherapy, it was not necessary to surgically remove the cyst lining, and there was no abscess formation.

Obtaining contrast radiographs of branchial cysts prior to sclerotherapy is essential in order to rule out any communication with the airways, oesophagus and other surrounding soft tissues.

In conclusion, marsupialization and sclerotherapy with an iodine and alcohol solution may be a less invasive yet viable alternative to surgical removal of branchial remnant cysts in horses.

\section{References}

1. Acierno, S.P., and Waldhausen, J.H.T. 2007. Congenital cervical cysts, sinuses and fistulae. Otolaryngol. Clin. North Am. 40: 161-176, vii-viii. [Medline] [CrossRef]

2. Agaton-Bonilla, F.C., and Gay-Escoda, C. 1996. Diagnosis and treatment of branchial cleft cysts and fistulae. A retrospective study of 183 patients. Int. J. Oral Maxillofac. Surg. 25: 449-452. [Medline] [CrossRef]

3. Chung, T.L., Holton, L.H. 3rd., Goldberg, N.H., and Silverman, R.P. 2006. Seroma prevention using Mytilus edulis protein in a rat mastectomy model. Breast J. 12: 442-445. [Medline] [CrossRef]

4. Cordero-Schmidt, G., Wallenstein, M.B., Ozen, M., Shah, N.A., Jackson, E., Hovsepian, D.M., and Palma, J.P. 2014. Pulmonary hypertensive crisis following ethanol sclerotherapy for a complex vascular malformation. J. Perinatol. 34: 713-715. [Medline] [CrossRef]

5. David, F., Savard, C., Drolet, R., Alexander, K., Pang, D.S.J., and Laverty, S. 2008. Congenital branchial apparatus malformation in a Haflinger colt. Vet. Surg. 37: 3-11. [Medline] [CrossRef]

6. De Estrada, J., and Schumacher, J. 2013. Treatment of an 18-year-old mare for bilateral, branchial remnant cysts. Equine Vet. Educ. 25: 129-133. [CrossRef]

7. Field, J.R., Trout, D., and Physick-Sheard, P.W. 1990. Ablation of a congenital neck mass in a foal. Can. Vet. J. 31: 643-644. [Medline]

8. France, M.P., Sundberg, J.P., and Martinic, G. 2000. Branchial cysts in laboratory mice. J. Comp. Pathol. 123: 55-58. [Medline] [CrossRef]

9. Hance, S.R., Robertson, J.T., and Wicks, J.R. 1992a. Branchial cyst in a filly. Equine Vet. J. 24: 329-331. [Medline] [CrossRef]

10. Hance, S.R., Robertson, J.T., and Bukowiecki, C.F. 1992 b. Cystic structures in the guttural pouch (auditory tube di- 
verticulum) of two horses. J. Am. Vet. Med. Assoc. 200: 1981-1983. [Medline]

11. Hester, T.O., Jones, R.O., and Haydon, R.C. 1994. Anomalies of the branchial apparatus: a case report and review of embryology, anatomy and development. J. Ky. Med. Assoc. 92: 358-362. [Medline]

12. Huang, W.L., Wang, Y.Z., Lin, X., and Liu, B. 2010. [Treatment of renal cysts with imaging-guided percutaneous catheterization drainage and alcohol sclerosis]. Nan Fang Yi Ke Da Xue Xue Bao 30: 1670-1672 (in Chinese). [Medline]

13. Kelmer, G., Kramer, J., Lacarruba, A.M., Turnquist, S.E., Johnson, J.C., and Messer, N.T. 2007. A novel location and en bloc excision of a thyroglossal duct cyst in a filly. Equine Vet. Educ. 19: 131-135. [CrossRef]

14. Koch, B.L. 2005. Cystic malformations of the neck in children. Pediatr. Radiol. 35: 463-477. [Medline] [CrossRef]

15. Mahrer, A., Ramchandani, P., Trerotola, S.O., ShlanskyGoldberg, R.D., and Itkin, M. 2010. Sclerotherapy in the management of postoperative lymphocele. J. Vasc. Interv. Radiol. 21: 1050-1053. [Medline] [CrossRef]

16. Maran, A.G., and Buchanan, D.R. 1978. Branchial cysts, sinuses and fistulae. Clin. Otolaryngol. Allied Sci. 3: 77-92. [Medline] [CrossRef]

17. Nolen-Walston, R.D., Parente, E.J., Madigan, J.E., David, F., Knafo, S.E., and Engiles, J.B. 2009. Branchial remnant cysts of mature and juvenile horses. Equine Vet. J. 41: 918-923. [Medline] [CrossRef]

18. Slovis, N.M., Watson, J.L., and Couto, S.S. 2001. Marsupialization and iodine sclerotherapy of a branchial cyst in a horse. J. Am. Vet. Med. Assoc. 219: 338-340, 324-325. [Medline] [CrossRef]

19. Smith, D.F., and Gunson, D.E. 1977. Branchial cyst in a heifer. J. Am. Vet. Med. Assoc. 171: 64-66. [Medline]

20. Waldhausen, J.H. 2006. Branchial cleft and arch anomalies in children. Semin. Pediatr. Surg. 15: 64-69. [Medline] [CrossRef] 